\title{
Visual outcome following posterior capsule rupture during cataract surgery
}

\author{
Alexander Ionides, Darwin Minassian, Stephen Tuft
}

\begin{abstract}
Aim-To determine the relative risk of a poor visual outcome following posterior capsule rupture during cataract surgery.

Methods-Prospective data were collected on consecutive eyes undergoing cataract extraction. The patient's age, preoperative visual acuity, ocular comorbidity, grade of surgeon, and operative complications were documented. The best spectacle corrected visual acuity was recorded at discharge from the hospital service.

Results-From a total of 1533 cases, 1420 $(\mathbf{9 2 . 6} \%)$ eyes had complete follow up data. Posterior capsule rupture occurred in 59 $(4.1 \%)$ cases. Eyes with posterior capsule rupture were 3.8 times more likely to have a final best spectacle corrected visual acuity less than 6/12.

Conclusions-Eyes having posterior capsule rupture during cataract surgery have a significant risk of reduced visual acuity. (Br F Ophthalmol 2001;85:222-224)
\end{abstract}

Posterior capsule (PC) rupture is a common intraoperative complication of cataract surgery $^{1}$ and may be associated with a poor visual outcome $\mathrm{e}^{2-6}$ owing to cystoid macular oedema and retinal detachment. ${ }^{7-10}$ Some studies have shown a reasonable visual outcome (visual acuity of 6/12 or better) in eyes following PC rupture, ${ }^{11-14}$ or even no statistically significant difference in the visual outcome when compared with controls. ${ }^{15}$ These studies were undertaken on patients undergoing extracapsular cataract extraction without phacoemulsification. Since the introduction of routine phacoemulsification, no studies have assessed the visual outcome after PC rupture when compared with controls. ${ }^{16}{ }^{17}$ Owing to increased interest in surgical outcomes with regard to clinical governance, the risk of decreased visual outcome following surgery is of considerable importance. We have examined a consecutive series of patients undergoing cataract surgery and compared the final spectacle corrected visual acuity of eyes with capsular complications with those who had uncomplicated surgery.

\section{Patients and methods}

Data were collected prospectively on a consecutive series of eyes undergoing cataract extraction and intraocular lens (IOL) insertion between 1996 and 1999. All patients were under the care of one consultant (ST), but surgeons at different grades of training performed the surgery. Details regarding the intended surgery, grade of surgeon, presence of ocular comorbidity, preoperative acuity, and best spectacle corrected postoperative visual acuity were documented. Patients were excluded if they had cataract surgery combined with a second procedure. Those who underwent surgery that intentionally left them aphakic $(n=3)$ for clinical indications (for example, phacolytic glaucoma) were also excluded, but myopic patients having plano power implants or no IOL were included. Posterior capsule rupture was defined as a tear in the posterior capsule identified at the time of surgery. Vitreous loss was managed by mechanical anterior vitrectomy and insertion of a sulcus fixated or anterior chamber lens. Zonular detachment was defined as a dehiscence sufficient to require a modification of the surgical technique-for example, insertion of a capsular tension ring or a rigid intraocular lens.

All refractions were performed by hospital based optometrists. Patients were routinely seen 3 weeks after uncomplicated phacoemulsification surgery when spectacles were prescribed. Final review after extracapsular surgery was 1 month after corneal suture removal. Any patients who had additional complicating factors at either the time of surgery or during the postoperative period were seen at intervals indicated by the clinical situation. The final corrected visual acuity was recorded when no further treatment was planned and the patient was discharged from hospital follow up. The follow up times therefore varied between the two groups, as patients who had PC rupture took longer for their refraction to stabilise.

Multiple logistic regression analysis was used to estimate the odds ratio with adjustments for confounding effects of other prognostic factors (for example, type of surgery, surgeon grade, age). The logistic regression model incorporated "random effects" terms to take into account the extrabinomial variability arising from the data on two eyes per patient.

\section{Results}

Data on 1533 consecutive cataract operations were available. Of these, $13(0.8 \%)$ were excluded owing to missing data on peroperative complications and $100(6.5 \%)$ were excluded because of missing data on postoperative visual acuity (these patients were still under follow up in the clinic). The remaining 1420 cases consisted of 1155 (81.3\%) eyes with no preoperative risk factors (the main focus of the analysis) and $265(18.7 \%)$ eyes with ocular comorbidity identified before surgery. Of these, 60 patients had retinitis pigmentosa, 46 had age related macular degeneration, and 38 had high myopia. The remaining cases with ocular comorbidity consisted mainly of corneal scarring, previous retinal detach- 
Table 1 Complications at the time of surgery and visual outcome

\begin{tabular}{|c|c|c|c|c|c|c|}
\hline \multirow[b]{2}{*}{ Group } & \multirow[b]{2}{*}{ Complications at surgery } & \multirow[b]{2}{*}{ Procedures } & \multicolumn{3}{|c|}{ Best corrected postoperative vision } & \multirow[b]{2}{*}{ Fisher "exact" $p$ value } \\
\hline & & & $<6 / 12$ & $(\%)$ & Risk ratio $[95 \% \mathrm{CL}]$ & \\
\hline \multicolumn{7}{|c|}{ No ocular comorbidity: } \\
\hline A (referent) & No complications & 1043 & 57 & $(5.5)$ & Referent & \\
\hline $\mathrm{B}$ & PC tear & 50 & 10 & $(20.0)$ & $3.7[2.0-6.7]$ & 0.0005 \\
\hline $\mathrm{C}$ & Other complications & 62 & 7 & (11.3) & $2.1[1.0-4.3]$ & 0.0832 \\
\hline \multicolumn{7}{|c|}{ Ocular comorbidity: } \\
\hline A (referent) & No complications & 234 & 114 & $(48.7)$ & Referent & \\
\hline $\mathrm{B}$ & PC tear & 9 & 6 & $(66.7)$ & $1.4[0.9-2.2]$ & 0.3295 \\
\hline $\mathrm{C}$ & Other complications & 22 & 13 & $(59.1)$ & $1.2[0.8-1.8]$ & 0.3807 \\
\hline Table totals & & 1420 & & & & \\
\hline
\end{tabular}

Note. Comparisons under "Ocular comorbidity" are problematic and difficult to interpret due to number of diagnoses.

Table 2 Complications at surgery and corrected postoperative visual acuity (number (\%))

\begin{tabular}{|c|c|c|c|c|c|}
\hline \multirow[b]{2}{*}{ Complication at surgery } & \multirow{2}{*}{$\begin{array}{l}\text { Cataract } \\
\text { procedures }\end{array}$} & \multicolumn{3}{|c|}{ Best corrected postoperative visual acuity } & \multirow[b]{2}{*}{$<6 / 12$} \\
\hline & & $\geqslant 6 / 9$ & $6 / 12-6 / 18$ & $<6 / 18$ & \\
\hline \multicolumn{6}{|l|}{ No ocular comorbidity: } \\
\hline No complication & 1043 & $931(89.3)$ & $90(8.6)$ & $22(2.1)$ & $57(5.5)$ \\
\hline PC tear only & 17 & $14(82.4)$ & $1(5.9)$ & $2(11.8)$ & $3(17.6)$ \\
\hline PC tear and vitrectomy & 33 & $18(54.5)$ & $12(36.4)$ & $3(9.1)$ & $7(21.2)$ \\
\hline Anterior capsule tear & 45 & $36(80.0)$ & $7(15.6)$ & $2(4.4)$ & $2(4.4)$ \\
\hline Zonular detachment & 10 & $7(70.0)$ & $1(10.0)$ & $2(20.0)$ & $2(20.0)$ \\
\hline Other ${ }^{\star}$ & 7 & $3(42.3)$ & $3(42.9)$ & $1(14.3)$ & $3(42.9)$ \\
\hline Totals & 1155 & & & & \\
\hline \multicolumn{6}{|l|}{ Ocular comorbidity: } \\
\hline No complication & 234 & $75(32.21)$ & $75(32.1)$ & $84(35.9)$ & $114(48.7)$ \\
\hline PC tear only & 1 & 0 & 1 & 00 & $0(0.0)$ \\
\hline PC tear and vitrectomy & 8 & 0 & $3(37.5)$ & $5(62.5)$ & $6(75.0)$ \\
\hline Anterior capsule tear & 15 & $3(20.0)$ & $5(33.3)$ & $7(46.7)$ & $9(60.0)$ \\
\hline Zonular detachment & 7 & $1(14.3)$ & $2(28.6)$ & $4(57.1)$ & $4(57.1)$ \\
\hline Other & 0 & & & & \\
\hline Totals & 265 & & & & \\
\hline Table totals & 1420 & & & & \\
\hline
\end{tabular}

^Breakdown of other: Descemet's membrane strip 1, iris prolapse 4, suprachoroidal haemorrhage 1, wrong IOL inserted and exchanged, 1 . Total $=7$.

ment, and amblyopia. The high proportion of patients in this group affected by retinitis pigmentosa and the low number affected by glaucoma or diabetes reflects the case mix of this cataract service. Of the 1420 cases, 337 patients had undergone cataract extractions on both eyes, while the remaining patients had one procedure. Phacoemulsification was performed in $96 \%$ of eyes, and the supervising consultant performed $29 \%$ of all operations. The median follow up time was 3.1 weeks $(2-5$ weeks in $84 \%$ ). In the group with PC rupture the median follow up was 19.3 weeks (range 2.6-150.3 weeks).

A total of $59(4.1 \%)$ eyes had a PC tear at surgery. A PC tear occurred in five $(1.2 \%)$ of the consultant surgical cases and $54(5.3 \%)$ of the cases performed by surgeons in training. When compared with eyes that had uncomplicated surgery, the relative risk of having a final visual acuity worse than $6 / 12$ for eyes that had a PC tear was 3.7 (2.0-6.7, 95\% confidence limits) (Table 1). This is a crude calculation not including confounding factors. The risk of poor visual outcome (final visual acuity $<6 / 12$ ) in relation to PC tear at the time of surgery was also estimated by multiple logistic regression analysis with adjustment for possible confounding effects of other prognostic factors. The adjusted odds ratio was 3.8 (1.3-10.8, $95 \%$ confidence limits). As expected, patients with ocular comorbidity had a reduced visual acuity following uneventful cataract surgery and there was no statistically significant reduction in their visual outcome following PC rupture. In eyes with no ocular comorbidity and, thus, a good potential visual outcome, four of $50(8.0 \%)$ eyes with a PC tear had a final acuity that was worse than before the surgery, while 10 of $1105(0.9 \%)$ eyes without a PC tear had a similar visual deterioration.

COMMENT ON OTHER COMPLICATIONS

This group is made up of the other peroperative complications detailed in Table 2. The commonest was a peripheral anterior capsule tear extending from the continuous curvilinear capsulorhexis, which was not associated with an increased risk of a poor visual outcome.

\section{Discussion}

A PC tear is the commonest operative complication of extracapsular cataract surgery that can affect the postoperative visual acuity. In this outcome study $4.1 \%$ of eyes had a PC tear at the time of surgery, which is similar to the rate of $4.4 \%$ reported in the National Cataract Surgery Survey for 1997 to $1998 .{ }^{17}$ The visual outcome of $94.5 \%$ of eyes without comorbidity achieving a final spectacle corrected visual acuity of $6 / 12$ or better is again similar to the $92 \%$ reported in the National Cataract Surgery Survey. The percentage of cases performed by a consultant surgeon is lower than the reported national average, ${ }^{17}$ reflecting the training commitment at this hospital. Although a PC tear was more frequent in cases performed by surgeons in training, and although eyes that had a PC tear were at increased risk of a poor visual outcome, we could not demonstrate a statistically significant effect of the grade of surgeon on the overall final visual outcome. 
By comparing the outcome of eyes that had a PC tear during cataract extraction with eyes that did not, we have confirmed the detrimental effect of a PC tear on postoperative visual acuity. After adjustment for the possible confounding effects of age and grade of surgeon, PC tear remains a significant risk factor for poor a visual result (a corrected visual acuity of $<6 / 12$ ). The odds ratio of 3.8 suggests that in eyes without any ocular comorbidity identified preoperatively the risk of poor visual outcome was 3.8 times higher in eyes that had a PC tear, compared with those that had no complications at surgery. This figure is very close to that obtained after a crude analysis, which gave a statistically significant relative risk of 3.7. The odds ratios reported for the other "prognostic factors" are incidental and are reported for completion. Among these, old age (>80 years) carries the greatest risk. It should be noted that for uncommon risks a lack of statistical significance ( $p$ values $\geqslant 0.05$ ) does not necessarily indicate that there is no association between that factor and a risk of poor outcome.

There were insufficient cases in this series to permit a subgroup analysis of the visual impact of the complications that can accompany a PC rupture, such as a dropped nucleus or retained lens fragments, or to determine whether vitreous loss affected the outcome compared with a PC tear in isolation. It was a pragmatic decision to apply a cut off for observation at the time of discharge from the hospital service. We acknowledge that although cystoid macular oedema is the most important reason for early visual loss after a PC tear our method may underestimate a further loss of vision from late complications such as retinal detachment.
1 Desai P. The National cataract surgery survey: II Clinical outcomes. Eye 1993;7:489-94.

2 Vail D. After results of vitreous loss. Am f Ophthalmol 1965; B59:573-86.

3 Balent A, Civerchia LL, Mohamadi P. Visual outcome of cataract extraction and lens implantation complicated by vitreous loss. 7 Cataract Refract Surg 1988;14:158-60.

4 Pearson PA, Owen DG, Maliszewski M, et al. Anterior chamber lens extraction after vitreous loss. Br f Ophthalmol 1989;73:596-9.

5 Siepser SB, Kline OR. Aborted posterior chamber intraocular lens insertions: A 'second choyce'. Am Intraocular Lens Soc F 1984;10:51-2.

6 Hingorani M, Wong T, Vafidis G. Patients' and doctors' attitudes to amount of information given after unintended injury during treatment: cross sectional questionnaire survey. $B M F$ 1999;318:640-1.

7 Jaffe NS, Clayman HM, Jaffe MS. Cystoid macular edema after intracapsular and extracapsular cataract extraction with and without an intraocuar lens. Ophthalmology 1982;89:25-9.

8 Frost NA, Sparrow JM, Strong NP, et al. Vitreous loss in planned extracapsular cataract extraction does lead to a poorer visual outcome. Eye 1995;9:446-51.

9 Cerasoli JR, Kasner D. A follow-up study of vitreous loss during cataract surgery managed by anterior vitrectomy. Am f Ophthalmol 1971;71:1040-3.

10 Johansen J, Theodorsen FP, Corydon L. Visual outcome following complicated extracapsular cataract extraction. $\mathcal{f}$ Cataract Refract Surg 1992;18:577-81.

11 Osher RH, Cionni RJ. The torn posterior capsule: its intraoperative behaviour, surgical management and long term consequences. 7 Cataract Refract Surg 1990;16:490-4.

12 Spigelman AV, Lindstrom RL, Nichols BD, et al. Visual results following vitreous loss and primary lens implantation. F Cataract Refract Surg 1989;15:201-4.

13 Ah-Fat FG, Sharma MK, Majid MA, et al. Vitreous loss during conversion from conventional extracapsular cataract extraction to phacoemulsification. I Cataract Refract Surg 1998;24:801-5.

14 Thomas R, Naveen S, Jacob A, et al. Visual outcome and complications of residents learning phacoemulsification. Indian f Ophthalmol 1987;45:215-9.

15 Ishi O. Vitreous loss in posterior chamber lens implantation. 7 Cataract Refract Surg 1987;13:424-7.

16 Cruz OA, Wallace CW, Gay CA, et al. Visual results and complications of phakoemulsification with intraocular lens implantation performed by ophthalmology residents. Ophimplantation performed by opht
thalmology 1992;99:448-452.

17 Desai P, Minassian D, Reidy A. National cataract surgery survey 1997-8: a report of the results of the clinical outcomes. Br f Ophthalmol 1999;83:1336-40. 